\title{
Contribuições para uma Teoria Psicanalítica da Percepção: Da Regressão Alucinatória à Coisa do Desejo
}

\author{
Juliano Moreira Lagoas ${ }^{1,2, *}$ (D) \& Daniela Scheinkman Chatelard² (D) \\ ${ }^{1}$ Centro Universitário de Brasília (UniCeub), Brasília, DF, Brasil \\ ${ }^{2}$ Universidade de Brasília (UnB), DF, Brasil
}

\begin{abstract}
RESUMO - Este artigo busca examinar as relações entre percepção, realidade psíquica e desejo sob a perspectiva da psicanálise freudiana. Na primeira parte do trabalho, tratou-se de mostrar que o "esquema" do aparelho psíquico proposto por Freud na Interpretação dos sonhos (1900), evidenciando o mecanismo da regressão alucinatória, descortina a estrutura temporal do desejo, no interior da qual o problema da percepção recebe um sentido propriamente psicanalítico. Na segunda parte, vimos que o aparecimento da noção de das Ding (a Coisa), já no Projeto de uma psicologia (1895), demonstra que o campo dos fenômenos perceptivos se articula em função da relação do sujeito ao "próximo" (Nebensmensch), e, consequentemente, à Coisa do desejo, no enfrentamento do desamparo constitutivo da vida psíquica.
\end{abstract}

PALAVRAS-CHAVE: percepção, desejo, realidade psíquica, Freud, Lacan

\section{Contributions to a Psychoanalytic Theory of Perception: The Hallucinatory Regression to the Thing of Desire}

\begin{abstract}
This article seeks to examine the relationships between perception, psychic reality, and desire from the perspective of Freudian psychoanalysis. In the first part of the study, the "scheme" of the psychic apparatus proposed by Freud in The Interpretation of Dreams (1900), presenting the mechanism of hallucinatory regression, was demonstrated as revealing the temporal structure of desire, within which the problem of perception receives an actual psychoanalytic sense. In the second part, the emergence of the notion of das Ding (the Thing), already present in Project for a scientific psychology (1895), is observed, indicating that the field of perceptual phenomena is articulated in terms of the relationship of the subject to the "fellow human being" (Nebensmensch), and, thus, to the Thing of desire, in addressing the constituent helplessness of psychic life.
\end{abstract}

KEYWORDS: perception, desire, psychic reality, Freud, Lacan

\section{OS ESQUEMAS FREUDIANOS DO APARELHO PSÍQUICO}

O primeiro "esquema" freudiano do aparelho psíquico, representado por meio das letras gregas " $\varphi \psi \omega$ ", é construído no Projeto de uma psicologia (1950[1895]/2003) a partir de um raciocínio que podemos escandir em três tempos. Primeiro, o aparelho, na medida em que é determinado por leis físicas, tem como função descarregar as quantidades que nele se apresentam $(\varphi)($ p. 176). Segundo, como essa descarga não pode se dar de qualquer maneira, pois depende de uma "ação específica" que modifique o mundo externo, é preciso que o aparelho seja capaz de inibir as passagens de energia, de retê-la de maneira organizada em seu interior $(\psi)$ até que as condições da realidade exterior se mostrem adequadas à descarga (p. 177). Finalmente, como, no nível dos sistemas $\varphi$ (percepção) e $\psi$ (memória), o aparelho só lida com quantidades, resta que a "informação" sobre a adequação do mundo externo - portanto, sobre sua qualidade

* E-mail: julianolagoas@hotmail.com

- Submetido: 09/09/2016; Aceito: 14/11/2016. 
de "ser real" - venha de outro lugar, de outro sistema $(\omega)$ (p. 186-188). Em resumo, tudo se passa como se a gênese do aparelho consistisse na acumulação progressiva de funções: primeiro, descarregar $(\varphi)$, depois, reter $(\psi)$, e depois ainda, informar $(\omega)$. Para chegar a essa concepção funcional do psiquismo, Freud partirá de uma distinção fundamental no que diz respeito aos neurônios que o constituem: de um lado, os que deixam passar todas as quantidades, não oferecendo nenhuma resistência, formando o sistema da percepção, e, de outro lado, os que "só deixam passar a $\mathrm{Q} n$ com dificuldade ou só parcialmente" (p. 179), constituindo o sistema da memória. É, com efeito, sobre a relação de exclusão mútua entre percepção $(\varphi)$ e memória $(\psi)$ que se assenta o "primeiro esquema" freudiano do psiquismo.

Deve-se observar, desde já, que o surgimento de cada uma das funções do sistema não representa simplesmente um acréscimo em relação à anterior, tampouco sua hipóstase. Ao contrário, quando surge uma nova função, as anteriores se modificam. A hipótese da inibição (o segundo tempo), descrevendo os modos pelos quais o aparelho retém energia ao invés de descarregar, flexiona a tendência à descarga (o primeiro tempo) em tendência à constância. Por sua vez, a hipótese da informação (o terceiro tempo), explicando que os processos secundários (a inibição) só se articulam aos processos primários (a descarga) através de uma referência extrínseca a ambos, transforma a tendência à constância em tendência ao adiamento. E desta última, é preciso dizer que, ao contrário de sintetizar as duas tendências anteriores (descarga e constância), nomeia a existência de um impasse no cerne do aparelho psíquico, literalmente alguma coisa que não passa no circuito inibição-descarga, e que, nesse sentido, encontra-se aí interditada. Aos processos correspondentes às duas primeiras tendências - descarga e constância -, Freud chamará de "primários". Aos correspondentes a essa "nova" tendência, e para indicar a posteridade de seu surgimento, designará como "secundários"1.

Mas qual será a relação entre essas letrinhas, $\varphi \psi \omega$, escritas com a tinta monocromática das quantidades, e a realidade exterior, que Freud justamente não designa por letra nenhuma, e da qual ele diz apenas que o aparelho $\varphi$, isto é, os órgãos sensoriais situados na periferia do psiquismo, é o que está mais próximo, mas que, dela, não conserva

1 No artigo metapsicológico sobre $O$ Inconsciente, Freud (1915/2006a, p. 37) indica em nota que essa distinção se apoia nos trabalhos de Breuer nos Estudos sobre a histeria (1893-1895). Assoun (1983) esclarece que a distinção entre processos primários e secundários, originada da dualidade "energia livre"/"energia cativa" constitui "apenas a transposição de um par resgatado de numerosas teorias físicas e psicofisiológicas no decorrer do século XIX: energia cinética/energia estática, energia atual/energia potencial; e isso, na família desse energetismo mitigado ou mecanicismo energetizado que Ostwald resgatava para dele distinguir-se" (p. 205). É importante, em todo caso, notar que a energia, para Freud, não designa uma "Entidade" ou uma "coisa" circulando no interior do aparelho, mas um "tipo de processo agindo no psiquismo e etiquetado de "energético"" (p. 204). É por essa razão, explica Assoun (1983), que Freud "fala de processo (primário/secundário), onde Breuer fala em termos de tipos de energias (livre/cativa)" (p. 206). nenhum traço? Qual o papel dos fenômenos alucinatórios na estruturação do campo da percepção? Qual a relação entre desejo e percepção? E de que maneira o aparelho psíquico escapa à sugestão que lhe é feita pela estrutura da alucinação, a saber, de que o desejado é o percebido? São essas questões que motivam a discussão que tentaremos desenvolver neste artigo. Ao tentar determinar a relação do homem com a realidade externa, Freud se depara com uma dupla impossibilidade: o sistema $\psi$ não pode conhecê-la diretamente e o sistema $\varphi$ não pode registrá-la.

Na hiância entre percepção $(\varphi)$ e memória $(\psi)$, instaurase a exigência de um critério que garanta a mediação entre os dois aparelhos, quer dizer, que assegure a distância tópica entre eles, impedindo a reversão do sentido geral dos movimentos neuronais (a descarga) e, por conseguinte, a passagem direta das quantidades de $\psi$ para $\varphi$, o que resultaria forçosamente na alucinação do objeto que satisfaria as precisões internas do organismo. Apenas esse critério de verdade seria capaz de dar lugar ao "signo qualitativo" (Qualitätszeichen) da realidade, isto é, à informação, em $\omega$, de que, às representações internas fornecidas pelo sistema mnêmico $(\psi)$, corresponde um objeto real, presente na realidade externa (Freud, 1950[1895]/2003, p. 202-203) ${ }^{2}$. Mas porquanto diz respeito a uma ordem qualitativa, o critério precisa ser buscado alhures, ou seja, fora do regime quantitativo que domina os "processos primários" do funcionamento psíquico (p. 188). Se essa busca não tem melhor sorte, é em razão de uma impossibilidade estrutural, ou seja, inscrita nos próprios meios pelos quais ela se exerce. É, entretanto, essa impossibilidade que, inaugurando a tendência ao adiamento da descarga, e, consequentemente, deixando a satisfação suspensa ao surgimento de um "signo qualitativo", introduz o fato da percepção no horizonte do problema da verdade e da temporalidade, ou seja, da relação entre percepção, tempo e verdade. Problema cuja formulação apresenta-se ainda sob uma forma incipiente no Projeto de 1895.

Em contraste com o "primeiro esquema" do aparelho psíquico, de caráter notadamente mecânico, o "segundo esquema", apresentado na Interpretação dos sonhos (1900), revela uma dimensão temporal dos processos psíquicos, apontando, assim, para uma noção de realidade psíquica que exige, como seu corolário, o conceito de desejo. Partindo do "esquema" do aparelho psíquico proposto na Interpretação dos sonhos, tentaremos mostrar, na primeira parte do artigo, que o mecanismo da regressão alucinatória descortina a estrutura temporal do desejo, revelando a insatisfação como condição fundamental de constituição da realidade psíquica. Na segunda parte, veremos que o aparecimento da noção de das Ding (a Coisa), já no Projeto de uma psicologia

2 "Trata-se de um signo na medida em que nos avisa da presença de alguma coisa que se refere efetivamente ao mundo exterior, assinalando à consciência que é com esse mundo exterior que ela lida" (Lacan, 195960/2008a, p. 62). 
$(1895)^{3}$, reposiciona o "fato" da percepção no campo da verdade inconsciente, a partir do quê a articulação dos fenômenos perceptivos passa a ser concebida em função da relação do sujeito ao "próximo" (Nebensmensch), e, consequentemente, à Coisa do desejo, no enfrentamento do desamparo constitutivo da vida psíquica.

\section{A CONSTITUIÇÃO DO PSIQUISMO À DERIVA DA REALIDADE}

Em sua Observação sobre o relatório de Daniel Lagache, Lacan (1960/1998c) chama a atenção para o fato de Freud ter recusado, "na origem a todo sistema de qualquer de suas tópicas, a menor realidade, como aparelho diferenciado no organismo" (p. 656). Para se constituir, o psiquismo não encontra nenhum suporte na realidade externa. Se em seguida alguma realidade vai impor-se ao aparelho psíquico, é em razão dele ter se constituído inicialmente à deriva, sem nenhum lastro fora dos circuitos de prazer/satisfação que cria para si.

Desde o Projeto, Freud começava a se dar conta de que, no campo da experiência psíquica, não basta que alguma coisa do mundo exterior seja realmente percebida. Se o percebido não for adequado às precisões do organismo, se não estiver articulado aos interesses do aparelho psíquico, seu estatuto de "realidade" não terá nenhum valor prático, quer dizer, não poderá ser utilizado no sentido da satisfação das necessidades. Do ponto de vista econômico, a percepção só interessa ao sistema $\psi$ na medida em que for capaz de fornecer o substrato sensível para a formação dos "signos qualitativos" que permitam ao aparelho proceder à descarga (Freud, 1950[1895]/2003, p. 235).

No entanto, o que o "primeiro esquema" freudiano do psiquismo $-\varphi \psi \omega-$ demonstra é que os objetos da "percepção atual" se caracterizam originariamente por sua inadequação. Os "processos primários" e o mecanismo regressivo da alucinação atestam justamente essa inadequação. Já que, sob a pressão das quantidades endógenas, o aparelho alucina o objeto desejado $(\psi)$, o lugar da "percepção atual" fica reduzido ao de uma realidade "não-encontrada", porque ali onde o objeto aparece $(\varphi)$, falta o critério $(\omega)$ para distinguir sua verdade, quer dizer, para reconhecê-lo como "não-real". Nesse sentido, se não basta que o objeto seja realmente percebido, é porque ele precisa, antes, ser reconhecido. O que supõe, por sua vez, que sua percepção tenha sido repetida pelo menos uma vez, que ele reapareça no campo perceptivo ${ }^{4}$. No âmbito dos processos primários que dominam a gênese do aparelho, essa reaparição é necessariamente uma alucinação (p. 214) ${ }^{5}$.

3 Daqui em diante referido apenas como Projeto.

4 Lacan (1953-54/1986) exprime essa condição dizendo que "toda espécie de percebido comporta necessariamente a referência a um percebido anterior" (p. 74). Ou ainda, como afirma Jean Hyppolite (1954/1998) em seu Comentário sobre a Verneinung de Freud, "o sujeito reproduz sua representação das coisas a partir da percepção primitiva que teve delas" (p. 899).

5 "Quando só o processo primário está em jogo, o que acontece? Ele dá
Pois, se o trajeto descrito pela "primeira percepção" vai de $\varphi$ para $\psi$, do polo sensorial para o do seu registro mnêmico, a "segunda percepção", na medida em que a base do processo é, como veremos melhor mais adiante, a busca pela identidade com o que foi percebido anteriormente $(\psi=\varphi)$, só pode partir de $\psi$ para $\varphi$, ou seja, percorrer o caminho inverso àquele por meio do qual a imagem mnêmica se constituiu, devendo o aparelho, para isso, investi-la com uma quantidade endógena de energia que impulsione o trajeto. Essa quantidade, pelo fato de o aparelho ainda não dispor de um mecanismo que regule suas passagens ${ }^{6}$, não apenas reativa a imagem mnêmica, mas é transferida até $\varphi$, de tal modo que ela adquire a "completa vivacidade sensível" (Freud, 1900/2015, p. 571).

Mas poder-se-ia dizer que, sendo a "segunda percepção" necessariamente uma alucinação, ao menos a primeira teria sido "verdadeira", ou seja, referida, de fato, a algum objeto da realidade externa? Na resposta a essa questão reside, a nosso ver, uma dimensão essencial do conceito psicanalítico de realidade psíquica: na lógica dos acontecimentos psíquicos, a "primeira percepção" se reduz a uma imagem da qual o fenômeno alucinatório fornece a estrutura e as condições. Eis o sentido que devemos atribuir à afirmação de que "a recordação primária de uma percepção é necessariamente uma alucinação" (Freud, 1950[1895]/2003, p. 214): a primeira recordação é ela própria uma percepção... alucinatória. É porque o objeto é alucinado - e não recordado - que ele é percebido. A fórmula de Serge Lebovici esclarece essa condição de maneira exemplar: "o objeto é investido antes de ser percebido" (Lebovici citado por Angelergues, 1995, p. 455). Nesse sentido, Lavellée (1995) propõe a hipótese de que a "certeza perceptiva" se sustenta na "coloração" alucinatória da atividade perceptiva, sem a

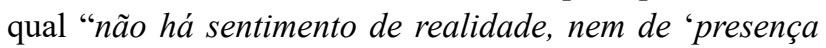
no mundo"" (p. 429). A alucinação, explica Lacan em seu Seminário de 1959-60, não designa nada menos do que uma condição para a constituição dos objetos da percepção:

No final das contas, sem algo que o alucine enquanto sistema de referência, nenhum mundo da percepção chega a ordenar-se de maneira válida, a constituir-se de maneira humana. $\mathrm{O}$ mundo da percepção nos é dado por Freud como que dependendo

na alucinação" (Lacan, 1958-59/2016, p. 77).

$6 \mathrm{O}$ que apenas o desenvolvimento ulterior dos mecanismos de inibição pelo "eu" tornará possível (Freud, 1950[1895]/2003, pp. 200-202). 
dessa alucinação fundamental sem a qual não haveria nenhuma atenção disponível. (Lacan, 1959-60/2008a, p. 68) ${ }^{7}$

Longe de apontar para uma abertura originária ao Ser, cortada em virtude de o aparelho ter enveredado na via alucinatória, Freud supõe que o próprio aparelho psíquico só tenha se constituído em razão de o percebido - o primeiro, o segundo ou o terceiro, pouco importa - ter sido alucinado. É aí, e não antes, que se efetua uma primeira abertura, não para o Ser, mas para a potência estésica, performativa, da imagem, para a possibilidade de uma presença que se impõe com toda evidência, mesmo - e principalmente - não havendo, dela, nenhum referente no mundo externo. "A alucinação traz consigo a convicção de tratar-se de uma realidade" (Freud 1917[1915]/2006b, p. 86). Não é difícil, certamente, identificar, no fundo dessa concepção estésica da imagem, a conjunção de um sensualismo da consciência e um espiritualismo da sensação, da qual a psicopatologia do século XIX - sobretudo aquela que grassou entre os alienistas franceses, na descendência de Esquirol, em Lélut, Moreau de Tours, Baillarger, etc. - retirou em grande medida seu fôlego ${ }^{8}$. O resultado é que se pôde definir, a partir daí, a alucinação como o "resultado um tanto compulsivo de um ato normal da inteligência, o mais alto grau de transformação sensorial da ideia" (Lélut citado por Bercherie, 1983, p. 133). De Locke a Condillac e aos alienistas franceses, a alucinação testemunha o "caráter essencialmente perceptivo das imagens mentais" (Bercherie, 1989, p. 66). Em 1870, Hippolyte Taine publicava sua obra De l'intelligence, na qual esse testemunho é levado às últimas consequências, isto é, ao ponto em que a economia da distinção entre imagem e sensação já quase não subsiste mais: "cada imagem é munida de uma força automática e tende espontaneamente a um certo estado que é a alucinação" (Taine, 1870/1892a, p. 139). O segredo do fenômeno alucinatório reside, de acordo com essa perspectiva, na capacidade que os centros sensoriais têm de "recriar a sensação na ausência do objeto" (Quercy, 1925 , p. 118). É a origem externa - digamos, objetal - da excitação que permite distinguir a sensação da imagem, esta "podendo ser chamada de sensação endógena, e a sensação propriamente dita, de sensação exógena" (p. 129). O acabamento dessa teoria será dado por Taine (1870/1892b), de uma maneira que não é menos surpreendente que desconcertante:

7 No Seminário Livro 6, Lacan afirma que "a realidade humana se constrói, segundo Freud, sobre um fundo alucinatório prévio" (Lacan, 1958-59/2016, p. 49).

8 A esse respeito, cf. os estudos de Paul Bercherie sobre os "fundamentos da clínica" (1989, em especial pp. 57-69) e sobre "a gênese dos conceitos freudianos" (1983, em especial pp. 105-157)
Assim, nossa percepção exterior é um sonho de dentro que se encontra em harmonia com as coisas de fora; e, ao invés de dizer que alucinação é uma percepção exterior falsa, é preciso dizer que a percepção é uma alucinação verdadeira. (p. 13) ${ }^{9}$

Assim, Taine não apenas atribui à alucinação uma dimensão eminentemente sensível, mas define a própria percepção como uma "alucinação normal” (Soler, 2007, p. 30). Mesmo que Freud nunca tenha feito qualquer referência explícita à teoria taineiana da percepção ${ }^{10}$, não nos parece ilegítimo perguntar: como a psicanálise freudiana se situa face à generalização do funcionamento alucinatório ao conjunto da vida perceptiva, e, mais geralmente, da vida psíquica?

Para responder a essa questão, devemos levar em conta, desde já, que o paralelismo psicofísico se imprime com todo vigor na démarche freudiana: a cada fenômeno da vida mental, corresponde uma modificação eficaz na realidade física, no cérebro. Aquilo que o sujeito percebe por meio de suas faculdades psíquicas (memória, atenção, pensamento, etc.) não é outra coisa senão o "avesso epifenomenal" do que ocorre no neurônio (Lacan, 1954-55/1985a, p. 184). A realidade física se configura assim como um núcleo irredutível da experiência psicológica. E é isso que nos adverte de não acolher, sem mais, no interior da teoria psicanalítica, a ideia de uma alucinação generalizada, apanágio do espiritualismo taineiano. Mas vale a pena insistir que o tratamento que Freud dá ao problema das alucinações é repleto de nuances e assaz sutil para que possamos resumir a resposta à questão acima em uma sentença definitiva e peremptória. Vejamos mais perto em que sentido as coisas se encaminham no interior do percurso freudiano.

Não basta, para Freud, descrever os fenômenos alucinatórios. É preciso, mais do que isso, explicar as idiossincrasias de sua constituição, sua dimensão eminentemente conflitual, e, principalmente, retomá-los sob o ângulo das consequências que eles introduzem na experiência e que retroagem sobre seus processos estruturantes. Nesse sentido, realizar um esboço do enquadramento dado por Freud ao conceito de "regressão" não será uma tarefa vã.

\footnotetext{
9 Cf. Bercherie, 1983, p. 135.
}

10 A título de curiosidade, é interessante mencionar o fato de que Freud leu De l'intelligence (1870/1892) de Taine, como se pode constatar em sua Carta de 13.02.1896 a Fliess. É verdade que a referência é enigmática e pouco precisa, pois Freud diz apenas que está ocupado com a metapsicologia e que o livro de Taine lhe "caiu extraordinariamente bem" (Masson, 1986, p. 173). 


\section{REGRESSÃO ALUCINATÓRIA, REPETIÇÃO E DESEJO}

Reconstruir as funções psíquicas a partir da sensação e do reflexo não é, seguramente, um traço distintivo do pensamento freudiano. Ao contrário, tudo o que se pôde colocar na esteira das filosofias empiristas do século XVIII sob a rubrica de "psicologia" - até o início do século XX - teve, em alguma medida, relação com a tentativa de induzir as ditas funções superiores (pensamento, julgamento, memória, etc.) a partir de complexos de reações elementares (sensação e percepção). Em Freud, não é diferente. Ou, pelo menos, não é isso que difere seu percurso, o naturalismo. Todavia, o ponto de partida e a inspiração sendo os mesmos, os caminhos adotados, a maneira de tratar os obstáculos e, consequentemente, os resultados, não o são. Não é desnecessário lembrarmos que, se Freud se interessa pelo caráter estésico do fenômeno alucinatório, é na medida em que ele vê aí uma pista na direção da apreensão da lógica que preside a formação dos sonhos, ou, melhor dizendo, dos pensamentos oníricos. A esse respeito, Lacan (1973/1978) sublinha que, em Freud, o sonho não é como uma alucinação; esta que é como um sonho, no sentido em "que ele é alguma coisa de plenamente articulado" (p. 1508).

É por meio da análise dos sonhos que Freud aborda inicialmente o mecanismo das alucinações: impedida de escoar até o polo motor do aparelho, a corrente de $Q n^{11}$ proveniente de $\psi$ toma o sentido inverso, seguindo livremente em direção a $\varphi$ (Freud, 1950[1895]/2003, p. 214; 1900/2015, p. 571). Trata-se da "regressão alucinatória", comportando três dimensões fundamentais: tópica, concernente ao espaço percorrido pelas quantidades; temporal, no que diz respeito à evolução e ao desenvolvimento do aparelho psíquico; e formal, quanto aos métodos de expressão e representação empregados. Mas essas três dimensões não manifestam senão um único e mesmo fenômeno: o da retransformação de uma representação na imagem sensorial da qual originalmente derivou (Freud, $1900 / 2015$, p. 566, p. 571). Tal como evidencia um parágrafo acrescentado em 1914 ao final da seção B ("Regressão") do capítulo VII da Interpretação dos sonhos, "o mais antigo em termos temporais é ao mesmo tempo primitivo sob o aspecto formal e mais próximo da extremidade perceptiva na tópica psíquica" (p. 576).

Demarca-se aí um modo especial do funcionamento do psíquico, caracterizado, primeiro, pela interrupção, e, em seguida, pela reversão do sentido geral do movimento neurônico. Todo o problema evidentemente é o dar conta do paradoxo que consiste em afirmar que as excitações, oriundas de $\varphi$ (estímulos externos) ou de $\psi$ (estímulos endógenos), em determinadas circunstâncias, adotem um caminho reverso àquele para o qual a pressão quantitativa as impele, isto é, do polo sensorial $(\varphi)$ para o polo motor $(\omega)$, o que está

11 Notação utilizada por Freud, no Projeto, para designar as quantidades de investimento energético que circulam no interior do aparelho psíquico. A esse respeito confira Gabbi Jr., 2003, nota 3, p.24. explícito no modelo do arco reflexo (excitação-descarga). Nas palavras de Lacan, "aquilo que vem pelo sensorium deve ir pelo motorium, e se o motorium não funciona, isso volta atrás" (Lacan, 1964/1998a, p.147). No sonho, o sentido regrediente dos movimentos neuronais se explica pela paralisia motora do sonhador, e, sobretudo, pelo caráter alucinatório das ideias oníricas (Freud, 1950[1895]/2003, p.212-214). Em todo caso, que a excitação possa seguir numa via retrógada, eis o que parece ser o mais contrário ao esquema do aparelho psíquico proposto na Interpretação dos sonhos (1900/2015, p. 566, cf. Figura 1):

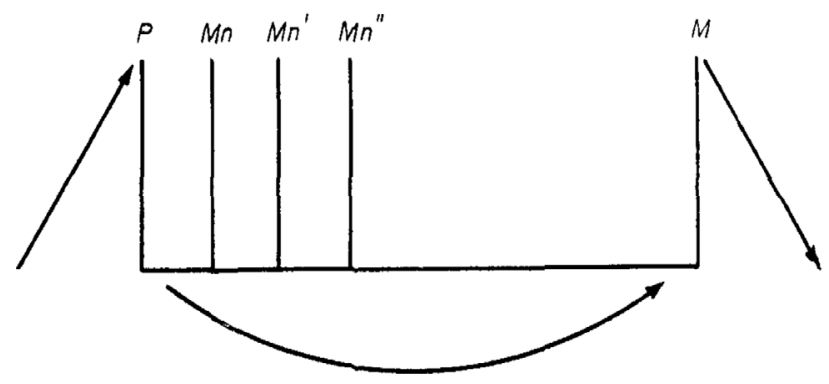

Figura 1: o "segundo esquema" freudiano do aparelho psíquico (Interpretação dos sonhos)

Numa extremidade, a percepção (P), na outra, a motricidade $(\mathrm{M})$; entre elas, os sistemas mnêmicos $(\mathrm{Mn}$, Mn', Mn") de inscrição e retranscrição que vão se formando à medida que a excitação progride no sentido de sua eliminação motora $(\mathrm{P} \rightarrow \mathrm{M})$. A característica fundamental dos processos psíquicos, diz Freud, é que eles têm um sentido, uma direção: "em geral, transcorrem da extremidade perceptiva à extremidade motora" (Freud, 1900/2015, p. 565). Significa dizer que, além de sua disposição espacial, o aparelho psíquico deve ser compreendido no interior de uma sequência temporal.

No Suplemento metapsicológico à teoria dos sonhos (1917[1915]/2006b), Freud dirá que a alucinação deve ser "mais do que a vivificação regressiva das imagens mnêmicas que se encontram em estado inconsciente" (p. 86). Que a percepção seja concebida como algo de elementar, quer dizer, dada de saída, anterior ao surgimento do menor sinal de consciência, a questão que advém daí é a de saber de que maneira os fenômenos perceptivos podem designar, na dinâmica psíquica, algo mais do que o mero efeito da capacidade receptiva dos órgãos sensoriais, e a alucinação, mais do que a reativação sensorial das imagens mnêmicas.

$\mathrm{O}$ caráter alucinatório das primeiras percepções não se explica num nível estritamente tópico - o investimento de $P$ a partir de $M n$ (Cf. fig. 1). É preciso, mais do que isso, que levemos em conta os efeitos "econômico" e "temporal" que a alucinação introduz: respectivamente, insatisfação e expectativa. Insatisfação, pois, como já dissemos, não podendo reconhecer o objeto percebido- 
alucinado como "não-real", o aparelho desencadeia a ação motora, permanecendo no estado de tensão original (Freud, $1950[1895] / 2003$, p. 197). E expectativa, pois a "desilusão" e o desprazer advindos dessa descarga "em falso" impõem uma nova coordenada para a satisfação: a de que o objeto encontrado "dentro" deva ser re-encontrado "fora", na realidade externa. Instaura-se, a partir daí, um horizonte temporal que se traduz num estado permanente de atenção e expectativa pelo reencontro com o objeto na percepção. À articulação entre insatisfação e expectativa, Freud chama "desejo". E é à regressão alucinatória que ele atribuiu sua realização primordial:

A criança faminta chorará ou se debaterá desamparadamente. Mas a situação permanece inalterada, pois a excitação proveniente da necessidade interna não corresponde a uma força que percute de maneira momentânea, mas a uma que atua de maneira contínua. Apenas pode ocorrer uma mudança quando, por uma via qualquer - no caso da criança, por uma assistência alheia -, se faz a experiência da vivência de satisfação, que elimina o estímulo interno. Um componente essencial dessa vivência é o surgimento de certa percepção (no exemplo, a percepção da nutrição), cuja imagem mnêmica daí por diante fica associada com o traço mnêmico da excitação da necessidade. Tão logo essa necessidade reapareça, resultará, graças à ligação estabelecida, uma moção psíquica que pretende investir outra vez a imagem mnêmica daquela percepção e causar novamente a própria percepção, ou seja, na verdade restabelecer a situação da primeira satisfação. Uma moção dessas é o que chamamos desejo [Wunsch]; o reaparecimento da percepção é a realização do desejo [Wunscherfüllung], e o investimento pleno da percepção por parte da excitação da necessidade é o caminho mais curto para a realização de desejo. Nada nos impede de supor um estado primitivo em que esse caminho é realmente percorrido dessa maneira, ou seja, em que o desejo termina num alucinar. Portanto, essa primeira atividade psíquica visa uma identidade perceptiva, isto é, a repetição daquela percepção que está ligada à satisfação da necessidade. (Freud, 1900/2015, p. 594)

Pela alucinação, o mundo da percepção perde seu caráter presumidamente neutro - isto que, de certa forma, está subentendido na localização dos processos perceptuais na extremidade sensorial (P), como anteriores a toda atividade psíquica - tornando-se, assim, o próprio mundo do desejo. A pretensa neutralidade da percepção desaparece no momento mesmo em que a "realização do desejo" se impõe como efeito econômico e temporal da regressão alucinatória. A atividade perceptiva permanecerá, doravante, indissociavelmente ligada a essa "moção" que impulsiona o psiquismo a repetir na percepção aquilo que, nos sistemas mnêmicos $(M n)$, só se dá como representação, como lembrança inconsciente, o que nos impede de conceber o percebido como algo de originário, dado de saída, quer dizer, limitado à extremidade sensorial do aparelho.

A experiência à qual Freud se refere na citação acima já havia sido descrita no Projeto, quer dizer, ao nível do "primeiro esquema" do psiquismo, sob a insígnia da "vivência de satisfação" (Freud, 1950[1895]/2003, p. 195-197). Mas no escopo do "segundo esquema", Freud diz que "o reaparecimento da percepção é a realização do desejo" (Wunscherfüllung) (Freud, 1900/2015, p. 594), ao invés de afirmar simplesmente, como o faz no Projeto, que a imagem mnêmica é "afetada pela animação desiderativa" (Wunschbelebung) ${ }^{12}$. Parece-nos que há aí uma diferença importante. O termo "realização" aponta para o fato de que a alucinação do objeto que satisfaria as precisões do organismo inaugura um domínio no qual aquilo que não tem existência no mundo externo, possui, no entanto, realidade. Assim, ao contrário de ser tomada como um obstáculo à satisfação das necessidades do organismo, a alucinação é precisamente o que inaugura, no psiquismo, uma possibilidade de realização a despeito da in(existência) do objeto no mundo externo: a realização do desejo, no sentido em que ela deve ser entendida na experiência analítica - no de tornar real uma insatisfação. E, uma vez a necessidade prolongada em desejo, o objeto que a satisfaria torna-se irremediavelmente perdido. Mais precisamente, com a alucinação do objeto da necessidade, ele se converte em objeto de desejo, na medida em que, reevocando-o, antecipa-se a presença de algo que não está mais presente. $\mathrm{O}$ que não quer dizer que o objeto tenha realmente estado presente ou existido - e "nada nos impede de supor" que ele o tenha - mas apenas que sua existência é inessencial no que concerne à constituição da realidade psíquica. É o desejo, diz Lacan (1966-67/2008b), que é "a essência da realidade" (p. 19).

A estrutura temporal do desejo, descortinada pelo esquema do aparelho psíquico da Interpretação dos sonhos, abre as comportas de uma verdade inaudita pelo pensamento filosófico e psicológico até Freud: aquilo que não existe, o objeto "alucinado-percebido", está aí para testemunhar o que há de frágil e improvável na existência daquilo que, para existir "realmente", precisa excluir seu passado, a história tateante e titubeante de sua constituição. A relação do homem com o mundo, diz Lacan (1954-55/1985a), "tem algo de profundamente, inicialmente, inauguralmente lesado" ( $\mathrm{p}$. 212). Nesse sentido, a alucinação não exprime outra coisa senão que, "do psiquismo, é a insatisfação que constitui o elemento primordial" (Lacan, 1967/2003, p. 354).

Mas, afinal, se a alucinação é o princípio estruturante do funcionamento psíquico, de que maneira o aparelho poderá escapar dessa "falsa realidade" à qual o fenômeno da percepção alucinatória predestina o organismo humano (Lacan, 1959-60/2008a, p. 55)?

12 "Assim, origina-se, por intermédio da vivência de satisfação, uma facilitação entre duas imagens recordativas e os neurônios nucleares que, no estado de incitação, são ocupados. Com a eliminação \{própria\} da satisfação, a Qn também é, sem dúvida, retirada das imagens re[cordativas]. Com o reaparecimento do estado incitante ou desiderativo, a ocupação prossegue agora também para ambas as re[cordações] e as anima. A imagem recordativa do objeto é certamente a primeira a ser afetada pela animação desiderativa" (Freud, 1950[1895]/2003, p. 197). 


\section{O OBJETO PERDIDO DO DESEJO, OU A COISA DA PERCEPÇÃO}

Enquanto as psicologias de matriz sensualistaassociacionista fiavam-se no critério da presença/ausência empírica do objeto na realidade externa para estabelecer a verdade/falsidade de uma percepção, de onde se deduz o aforismo segundo o qual 'alucinação é uma percepção sem objeto'13, Freud se esforçava por suspender a correlação, presumida inequívoca pela tradição, entre "objeto" e "mundo externo", por um lado, e entre "realidade psíquica" e "mundo interno", por outro. Ao invés de pressupor a presença do objeto no mundo externo como condição sine qua non para a percepção verdadeira, trata-se, para o fundador da psicanálise, de recuar aquém da noção pré-formada do objeto - quer dizer, em sua acepção clássica de ser extenso, desdobrado ponto a ponto no espaço - focalizando o momento crítico no qual o aparelho psíquico encontra-se totalmente incapaz de distinguir o que é interno do que é externo, para tentar apreender o nascimento do mundo objetal, experiência marcada fundamentalmente por um estado de expectativa, de "suspensão" do sujeito em relação "ao que constitui seu objeto fundamental, o objeto de sua satisfação essencial." (Lacan, 1955-56/1985b, p. 101). E ele está suspenso aí porque, ao contrário de uma abertura ao Ser, o que caracteriza a vida psíquica em sua origem é o esforço de obliteração da realidade pelo circuito fechado das regressões alucinatórias. Mas como, no fim das contas, a "curta via da regressão" não leva à satisfação real do desejo (Freud, 1917[1915]/2006b, p. 238), impõe-se a necessidade de um dispositivo que permita ao aparelho psíquico inibir o movimento regressivo - os processos primários - e chegar à situação perceptiva desejada ${ }^{14}$.

É, com efeito, em termos de identidade que o problema da verdade perceptiva é formulado no Projeto. A percepção "verdadeira" - aquela que supostamente proporcionaria uma "satisfação real do desejo" - depende de que o sistema $\psi$ seja capaz de regular as passagens de energia no interior do aparelho, de tamponá-las tanto quanto possível, mantendo os investimentos estabilizados em um nível tão baixo quanto possível: (a) comparar a percepção atual com a imagem mnêmica do objeto desejado, e, uma vez constatada a discordância entre eles, (b) influir sobre a percepção de modo a (re)estabelecer sua identidade ao desejado. O operador dessa regulação homeostática dos níveis de investimento do aparelho é ostensivamente designado por Freud: trata-se do

13 Essa definição de alucinação é estabelecida, conforme nos mostra Lanteri-Laura (2000), nas origens da clínica psiquiátrica moderna, isto é, com Esquirol (pp. 247-252). Sobre a concepção de alucinação como "percepção sem objeto", cf. Ball (1890, pp. 60-63). Vale mencionar que

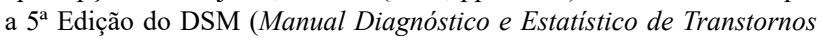
Mentais, 2014) traz a seguinte definição: "Alucinações são experiências semelhantes à percepção que ocorrem sem um estímulo externo" (p. 87).

14 "Foi preciso que não ocorresse a satisfação esperada, que houvesse uma frustração, para que essa tentativa de satisfação pela via alucinatória fosse abandonada" (Freud, 1911/2004, p. 66). "eu"15. A operação é denominada "pensamento", e o fator operativo, "signo qualitativo". Essa tríade "Eu-Pensamento - Signo qualitativo", é a partir dela que Freud nos ensina a situar o problema da verdade perceptiva no interior da economia psíquica.

Dizíamos anteriormente que, na gênese da vida psíquica, o lugar da percepção se reduz ao de uma realidade "nãoencontrada", em razão de o aparelho não dispor de "um signo para diferenciar percepção de recordação (ideia)" (Freud, 1950[1895]/2003, p. 202), ou seja, de um critério que lhe permita reconhecer o objeto alucinado como "nãoreal". É essa condição originalmente precária que será o motor para a atividade do pensamento. A discordância, diz Freud, "dá o impulso para o trabalho de pensar, que termina de novo com a coincidência" (p. 205). Ou, poderíamos dizer, com a "re-coincidência", na medida em que as três tendências fundamentais do aparelho-descarga, constância e adiamento, das quais falávamos no início deste artigo - estão ligadas a uma função, não de novidade, de produção do novo, mas de repetição, de retorno ao Mesmo da satisfação originária, ou, se quisermos, de busca pelo "objeto perdido". O fracasso dessa busca - atestado pela experiência alucinatória - ensina que é impossível atingir o Mesmo sem passar pelo Outro, sem o desvio pelas imagens mnêmicas (as recordações), pelo corpo (a motricidade), e pelo símbolo (o "signo qualitativo"). Ao contrário de se reduzir a uma "não-realidade", à ausência de realidade, ou ainda, à "quase-realidade" da qual falava o filósofo francês Maurice Merleau-Ponty (1945/1999, p. 448), a percepção alucinatória, pela via da qual o mundo dos objetos começa se constituir para o psiquismo, é justamente o que abre as portas para outra realidade. Comentando o artigo $A$ perda da realidade na neurose e na psicose (1924), Lacan (1958/1998b) observa que, para Freud, “o problema não é o da perda realidade, mas o expediente daquilo que vem substituí-la" (p. 549). É no processo dessa substituição que reside um dos segredos da categoria de "objeto" na experiência analítica: o objeto reencontrado nunca é o objeto procurado, mas sempre um substituto do objeto perdido ${ }^{16}$. Decorre daí o outro dos segredos: a ausência do objeto dá lugar à realidade da imagem e do símbolo. É nisso que Freud engaja o conceito de "pensamento" no Projeto: em

$\mathbf{1 5}$ Nos termos do Projeto, o "eu” designa uma massa de neurônios $\psi$ que permanece constantemente investida e, assim, atua como uma barreira que impede a passagem direta de $Q$ até $\varphi$ (Freud, 1950[1895]/2003, pp. 200-202).

16 Quanto a isso, Lacan esclarece que a perda do objeto não é um acontecimento na ordem cronológica dos fatos, ou seja, não pressupõe sua posse anterior, mas é ela mesma uma condição de sua constituição. "O objeto, diz Lacan, é por sua natureza um objeto reencontrado. Que ele tenha sido perdido, é a consequência disso - mas só-depois. E, portanto, ele é reencontrado, sendo que a única maneira de saber que ele foi perdido é por meio desses reencontros, desses reachados" (Lacan, 1959-60/2008b, p. 145). 
explicar que, na falta do objeto - e face o anacronismo da "identidade perceptiva" obtida pela via alucinatória - o caminho para satisfação do desejo só é tornado possível por um processo que lança o aparelho psíquico na errância das imagens e dos símbolos, e que, nesse movimento, revela a dependência estrutural do organismo humano em relação ao outro, ao próximo. Vejamos mais de perto em que consiste esse processo.

Em primeiro lugar, é preciso ter em conta o que Freud diz dos objetos da percepção: que eles não designam o investimento (Besetzung) de neurônios isolados, mas de complexos, cuja decomposição, "por meio da comparação com outros complexos perceptivos", revela um componente "que quase nunca muda", neurônio $a$, e outro, "que quase sempre varia", neurônio $b$ (Freud, 1950[1895]/2003, p. 205). Ao componente constante, Freud chamará "a Coisa" (das Ding), e ao componente variável, seu "predicado". O início da atividade do pensamento se dá quando, buscando o objeto desejado, representado pelo complexo $a+b$, o aparelho psíquico encontra, na percepção, o complexo $a+c$. Ou seja, no lugar do predicado $b$, desejado, surge o predicado $c$, percebido. A partir daí, diz Freud,

(...) o trabalho do eu segue as ligações desse neurônio $c$ e faz surgir, por meio da corrente de $Q n$, ao longo dessas ligações, novas ocupações, até encontrar um acesso para o neurônio faltante $b$. Em geral, resulta em uma imagem motora intercalada entre neurônio $c$ e neurônio $b$, e com a reanimação desta imagem, por um movimento efetivamente realizado, produz-se a identidade procurada. (p. 205) ${ }^{17}$

Importa, sobretudo, notar aqui que a transferência da $Q n$ do neurônio $c$, de origem externa, para $b$, de origem interna, pressupõe um fundo constante que não pertence, exclusivamente, nem ao complexo perceptivo, nem ao desiderativo, a saber, a Coisa (das Ding). A consequência é que, incomparável, já que invariável e sem qualidades, $a$ Coisa resta incompreensível, só podendo, por essa razão, ser repetida. A atividade do pensamento implica que pelo menos um elemento do complexo perceptivo seja não-rememorável, e que permaneça, a esse título, excluído da cadeia de rememorações. Mas excluído onde? No exterior, em alguma realidade transcendente? Tal questão nos oferece a oportunidade de afastar a suspeita de que o conceito de Coisa

17 É forçoso admitir, entretanto, que não se trata aqui de "identidade perceptiva" no sentido estrito, mas, antes, de "identidade de pensamento". A primeira se estabelece apenas no caso em que a excitação encontra passagem direta para a imagem mnêmica da percepção ligada à satisfação primária da necessidade, ou seja, nas alucinações. Se o trabalho de investimento pelo eu intervém, é porque o aparelho desistiu de empregar tal expediente, em razão da frustração e da consequente liberação de desprazer à qual a experiência mostrou que ele leva. "O processo primário almeja a descarga da excitação para, com a quantidade de excitação assim acumulada, produzir uma identidade perceptiva [com a vivência de satisfação]; o processo secundário abandonou essa intenção e em seu lugar assumiu outra, a de conseguir uma identidade de pensamento [com aquela vivência]" (Freud, 1900/2015, p. 630). (das Ding) denote, para Freud, algum tipo de "substância", no sentido metafísico. Realizando a passagem de $c$ para $b$, o pensamento evidencia "a similaridade que existe entre o núcleo do eu e o componente constante da percepção $[a$ Coisa], as ocupações mutáveis do manto e o componente inconstante [o predicado]" (Freud, 1950[1895]/2003, p. 205). Ao contrário de uma exterioridade inefável e inacessível, $a$ Coisa é aquilo com o que, do complexo perceptivo, o "eu" - ou, melhor dizendo, uma parte dele, seu núcleo - mantém uma relação de intimidade, de semelhança. Uma intimidade, entretanto, paradoxal, pois, não podendo ser associada a recordações de experiências vividas no passado, a Coisa se revela como algo de essencialmente estranho, ou, de acordo com o potente neologismo de Lacan (1959-60/2008b), como "extimidade", "exterioridade íntima" (p. 169).

É importante que não nos deixemos enganar por falsos paradoxos: se os termos "exterioridade íntima" e "extimidade" parecem tão antinômicos, ou mesmo mero recurso retórico, é porque partimos da ideia pré-concebida do "eu" como princípio metafísico da experiência, no sentido daquela "consciência de si" que Descartes semeou no terreno da reflexão filosófica e que a história do pensamento moderno fez florescer de maneira tão notável. Em Freud, ao contrário, a Coisa é precisamente o que rechaça o princípio da identidade da consciência a si mesma: o "exterior íntimo" que ela assinala não é senão a forma invertida do desconhecimento do eu em relação a si mesmo. Não apenas a Coisa é estranhamente íntima ao eu, mas este, por sua vez, é intimamente estranho a si mesmo. A suspensão da correlação imediata entre objeto e exterior, e entre realidade psíquica e interior, da qual falávamos acima, encontra no conceito de Coisa (das Ding) seu operador fundamental, na medida em que ele situa as relações do psiquismo com a realidade a partir de um movimento de interpenetração do interior e do exterior.

Diante da dessemelhança entre os complexos desiderativo $(a+b)$ e perceptivo $(a+c)$, o aparelho psíquico procede por interpolação de imagens motoras entre os elementos discordantes $b$ e $c$, desencadeando os movimentos efetivos correspondentes (imitação), os quais, por tentativa e erro, levam a uma ação que, como sublinha Freud (1950[1895]/2003), “já pertence ao lado acidental [isto é, contingente] da ação específica" (p. 206). O modelo desse procedimento é descrito no Projeto a partir do seguinte exemplo. A criança deseja ver o busto materno "em visão frontal", mas percebe-o em uma "visão lateral". Através do investimento da recordação de uma experiência na qual, após a amamentação, um "movimento determinado da cabeça transformou a imagem frontal em imagem lateral", a criança executa, em sentido contrário, o movimento recordado, chegando assim à "percepção da visão frontal" (p. 205). Trata-se de um exemplo extremamente simples, mas, segundo Freud, suficiente para demonstrar que, nos processos de pensamento, a migração da $Q n$ entre as imagens mnêmicas não é dominada pelos processos primários - 
segundo os quais as migrações das quantidades Q $n$ deveriam se realizar seguindo unicamente as vias facilitadas, as "trilhas" (Bahnn) abertas no sistema $\psi$ a partir da experiência de satisfação originária, como já sabemos, alucinatória ${ }^{18}$ mas por uma meta, uma finalidade: "retornar ao neurônio faltante $b$ e provocar a sensação de identidade, ou seja, o momento no qual apenas o neurônio $b$ é ocupado [investido], no qual a ocupação [investimento] migratória desemboca no neurônio $b "$ (p. 206). Esse retorno à identidade, desde que o aparelho tenha abandonado a via "direta" da alucinação $(c \leftarrow b)$, é através de um longo trabalho de deslocamentos, diferenciações, luta contra facilitações consolidadas da memória, que ele se realiza. A "não-coincidência" $(b \neq c)$ é o sinal para o início do trabalho do pensamento, que consistirá então em substituir c por $b$, evitando, para isso, a migração direta das quantidades de $b$ para $c$, como ocorre na regressão alucinatória. Tentemos representar a "atividade do pensar" por meio da Figura 2.

Para que a substituição ocorra, é preciso, de um lado, que a "ideia desiderativa [da] re[cordação] [isto é do neurônio $b$ ]" mantenha-se constantemente "investida enquanto se persegue a associação desde o neurônio c" (Freud, 1950[1895]/2003, p. 206), e de outro, que o núcleo dos complexos comparados $(a)$ permaneça invariável, sendo o ato da repetição a função que realiza essa invariabilidade. Em outras palavras, a substituição perseguida resulta de duas operações síncronas: o investimento moderado e constante de $b$ (a partir da $\mathrm{Q} n$ proveniente do "Eu") e a subtração da Coisa (das Ding) no processo de deslocamento dos investimentos ${ }^{19}$. Como explica Chatelard (2005), "todo o sistema de substituição apoia-se em das Ding, que organiza o idêntico e o diferente" (p. 105). Ao que acrescentaríamos: é pela função da repetição que esse apoio se realiza.

Mas da ideia d'a Coisa como apoio do sistema simbólico de substituições, não devemos concluir que ela seja um ponto de estabilidade ou um "referente externo" para os

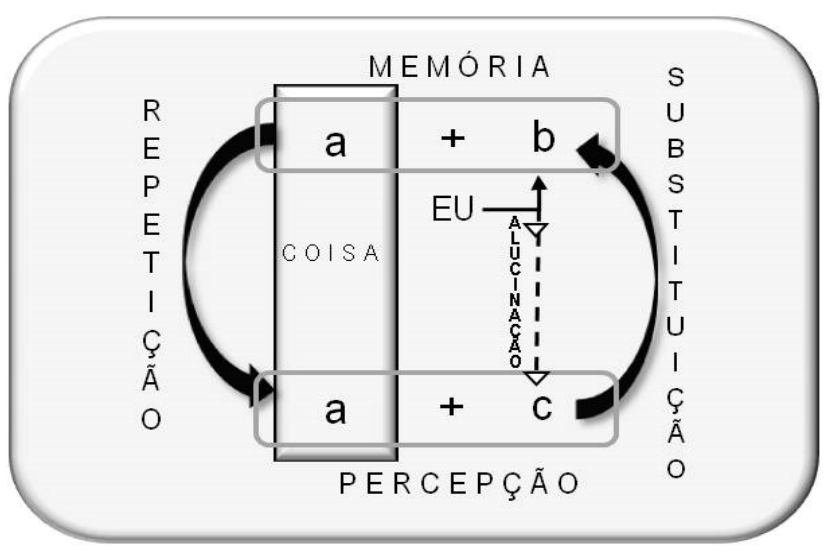

Figura 2: a "atividade do pensar"

deslocamentos que se realizam ao nível dos investimentos perceptivos do eu na busca pelo objeto de desejo. É justamente o contrário: a Coisa é o que nomeia o ponto de desarticulação do psiquismo em relação a toda referência à realidade externa, ou, de acordo com Iannini (2009), a "falha da referencialidade" (p. 22). E o que isso quer dizer senão que $a$ Coisa traduz a existência de algo que, não podendo ser representado, representa dessa forma a impossibilidade de que a representação se refira a uma entidade positiva independente do ato de representá-la, isto é, a um referente externo? Essa Coisa, diz Lacan, "será sempre representada por um vazio, precisamente pelo fato de ela não poder ser representada por outra coisa - ou mais precisamente de ela não poder ser representada senão por outra coisa" (Lacan, 1959-60/2008b, p. 158). Dito de outro modo, a Coisa se apresenta como aquilo que, da representação, representa a si mesmo no ato de representar o vazio. Ainda segundo Iannini (2000), o aparecimento d'a Coisa é o correlato do instante em que, no centro da linguagem, se inscreve um "vazio de referência" (Iannini, 2000, p. 62).

\section{O DESAMPARO FUNDAMENTAL E O TEMPO DA COISA}

Recuemos um passo atrás na sequência da argumentação do Projeto para tentar apreender o sentido em que $a$ Coisa surge na experiência como "vazio de referência" da linguagem. A entrada do organismo no universo da linguagem, explica Freud, responde à situação de desamparo (Hilflosigkeit) que marca a vida psíquica em sua origem, e que é "a fonte originária de todos os motivos morais" (Freud,

18 Caso os processos secundários já não tivessem intervido, restaria inexplicável por que, diante da "visão lateral" do busto materno, isto é, da dessemelhança entre o desejado e o percebido, o aparelho não alucina a imagem mnêmica do seio em "visão frontal", ao invés de desviar-se por imagens motoras, cuja inervação exige um dispêndio muito maior de energia.

19 "O que chamamos de coisas são restos subtraídos à apreciação" (Freud, 1950[1895]/2003, p. 210).
$1950[1895] / 2003$, p. 196 $)^{20}$. Tomemos ao pé da letra a dita necessidade biológica, por exemplo, de comer. Se a criança tem fome e o alimento está ao seu alcance, com um pequeno dispêndio motor, ela come e satisfaz sua necessidade. O que é significativo, no entanto, é que, se o alimento não está ao seu alcance - o que, via de regra, é o caso de um bebê - é preciso mais do que um pequeno dispêndio para cancelar o estímulo penoso de origem endógena (a fome), já que a satisfação, nesse caso, não pode ser atingida por uma "reação motora", mas apenas por uma "ação específica" (Freud, 1950[1895]/2003, p. 177). O que é "específico" nessa ação é o fato de que ela não diz respeito ao circuito reflexo que

20 Para uma discussão sobre os destinos e desenlaces da noção de "desamparo" (Hilflosigkeit) em Freud, cf. Massara (2010). 
comanda os processos primários do aparelho psíquico ${ }^{21}$, sua tendência à descarga/constância, devendo, portanto, vir de fora; em suma, só pode ser realizada com uma "ajuda externa" (p. 196).

A satisfação da criança, em virtude da falta de recursos do aparelho para responder às exigências da vida, encontra-se "inteiramente suspensa ao outro" (Lacan, 1959-60/2008b, p. 53). Em um primeiro momento, pode-se, é verdade, concluir daí que, "se o indivíduo prestativo realizou o trabalho da ação específica no mundo externo para o desamparado", então o estímulo endógeno é cancelado, e então a vivência de satisfação se terá realizado (Freud, 1950[1895]/2003, p. 196). O problema, entretanto, é que o "indivíduo prestativo" não é uma entidade abstrata, mas, ele próprio, um objeto da percepção, quer dizer, um "complexo perceptivo". E como tal, "divide-se em duas partes, uma das quais se impõe por meio de uma estrutura constante permanecendo junta como coisa (als Ding), enquanto a outra é compreendida pelo trabalho recordativo, isto é, pode ser rastreada até uma mensagem do próprio corpo" (p. 208). É certo que a percepção do outro não forma um complexo perceptivo qualquer, já que se trata de um "objeto" que é "ao mesmo tempo o primeiro objeto de satisfação e, além disso, o primeiro objeto hostil, assim como o único poder auxiliar" (p. 207). Nesse sentido, o outro constitui, para o sujeito, a primeira via de acesso tanto ao "objeto de satisfação" (e prazeroso), quanto ao "objeto hostil" (e, por conseguinte, desprazeroso). De onde se segue a ambivalência fundamental que marca a gênese das relações objetais no ser humano.

À percepção que a criança obtém do outro, Freud chamará "complexo do próximo", para distingui-lo dos demais complexos perceptivos, mas, sobretudo, para destacar sua prevalência na constituição da realidade psíquica. É na experiência do primeiro contato com o próximo (Nebenmensch) que a Coisa originalmente se manifesta, no momento em que, buscando decompor o complexo perceptivo dele proveniente, o sujeito se depara com algum traço (suas "feições", por exemplo) em relação ao qual ele não encontra, em seu próprio corpo, nenhuma mensagem com a qual possa associar. Um traço, portanto, para cuja comparação, o eu não dispõe de nenhuma referência, sendo justamente esse "vazio de referência" a condição para que, na impossibilidade da "identidade perceptiva", ao menos uma "identidade de pensamento" se estabeleça. No que diz respeito ao componente variável do "complexo do próximo" (por o exemplo, o "movimento das mãos"), o eu o identifica, pela atividade do pensar, tal como a explicitamos acima (cf. Fig. 2), a "re[cordações] motoras vividas por ele mesmo" (Freud, 1950[1895]/2003, p. 208).

21 Lacan ressalta que Freud não fala de "reação específica" (Lacan, 195960/2008b, p. 56).
Surpreendentemente, como nos mostra Gabbi Jr. (2003), "o caminho estabelecido entre as ideias resulta na produção de uma identidade inesperada: a identidade entre o corpo do outro e o próprio corpo" (p. 76) ${ }^{22}$. Com efeito, o outro primordial, único "objeto" da experiência ao qual a criança pode rogar auxílio na busca da "ação específica", revela-se sob duas faces, estruturalmente "não-complementares".

A primeira - "o outro elemento" - é feita à nossa imagem e semelhança, de modo que compreendo esse elemento tal como suponho que ele me compreende. Essa primeira face é meu semelhante, meu outro. A segunda - als Ding - está além do semelhante, é o próximo propriamente dito, o Outro inominável, fora do significado, estranho e estrangeiro a mim mesmo, imprevisível digamos, in-compreensível (sic), no sentido etimológico do termo: aquilo que não posso circunscrever. (Julien, 1996, p. 42)

O conceito d'a Coisa se revela fecundo em várias vertentes. É ele que nos permite compreender, por exemplo, em que sentido o "vazio de referência" pode se constituir, ele próprio, como uma referência para o psiquismo, como estofo da relação que, no eu, se estabelece entre prazer e realidade. $\mathrm{Ou}$, em outras palavras, permite compreender que uma referência não é algo de intrinsecamente positivo, uma entidade transcendente que regularia, de fora, as relações internas da vida psíquica. Ela pode muito bem orientar o aparelho sobre aquilo de que é preciso desviar-se. Mas, mais do que isso, a Coisa em Freud exige que pensemos a cisão interior/exterior como já sendo interna à própria constituição da relação do sujeito à realidade, que "não é stricto sensu 'o que existe no exterior', é o que o aparelho psíquico coloca como existindo no exterior, constituindo-se e se colocando ele mesmo como realidade de outra ordem" (Perron, 1995, p. 511).

Correlativamente, a Coisa prescreve, como um fato incontornável, a ambiguidade segundo a qual o sujeito experimenta o objeto como algo que foi perdido, mas que, ao mesmo tempo, só se constitui em função dessa perda. Segundo a feliz expressão de Bernard Baas (1992), o conceito de das Ding designa uma "perda anterior ao que foi perdido" (p. 52). Essa subversão da temporalidade do objeto, na relação assintótica do sujeito à realidade, configura o enquadramento geral no qual uma teoria da percepção deve recolher suas estruturas lógicas.

22 Se bem que não se trate, tal como nos adverte Gabbi Jr. (2003), de uma identificação com a imagem da totalidade do corpo do outro, não nos parecer impróprio dizer que a conjuntura apresentada por Freud aqui circunscreve, em toda a sua extensão, a problemática da constituição do eu e dos objetos, que será, sob a pena de Lacan, o mote para a elaboração daquilo que ficará consagrado como teoria do "estádio do espelho". A imagem do corpo do outro antecipa, dada a prematuridade biológica do organismo, a unidade imaginária do corpo-próprio. 


\section{CONSIDERAÇÕES FINAIS}

A presença do verdadeiro no campo percepção não se deduz simplesmente da possibilidade de que uma consciência venha assomar-se aos dados dispersos da sensibilidade. É preciso, antes, levar em conta que a imagem que confere unidade à dispersão dos dados sensíveis comporta uma ligação com alguma coisa que, subtraída na realidade, exclui-se no mais íntimo do ser do homem. Do mistério dessa ligação, é o desejo que guarda as chaves. $\mathrm{O}$ inconsciente é a via aberta pelo fato de que, daquilo que se compraz na inércia do prazer, resta sempre um núcleo de resistência a todo processo de reconhecimento, e que, a esse título, irrompe "na consciência sob a forma do visto" (Lacan, 1953-54/1986, p. 74), isto é, como realidade percebida.

O núcleo de resistência dos complexos perceptivos manifesta-se na experiência vivida sob a forma da evidência perceptiva. Em Além do princípio do prazer (1920/2006c), Freud afirma que "a consciência surge no lugar do traço de memória" (p. 150). Não é dizer, entretanto, que o traço de memória acede à consciência pela via da percepção, que o sujeito se recorde conscientemente de algo que estava esquecido no inconsciente, mas, antes, que ele "vê", logo, percebe, ao invés de recordar. Ou dito de outro modo, que sua visão é o avesso de algo que, no inconsciente, fora recordado. Com efeito, a memória de que se trata aqui só pode ser de natureza inconsciente, que é a única que verdadeiramente interessa a Freud (1900/2015, p. 569). E a distância em relação à Coisa (das Ding), sua subtração no processo de deslocamento das imagens mnêmicas, tem a função essencial de não nos deixar esquecer daquilo que não podemos lembrar. Afinal, como bem formula Lacan (1959-60/2008b), o inconsciente é a memória do que o sujeito esquece (p. 276).
Se, por um lado, o circuito fechado das alucinações enclausura o organismo nas "trilhas" do prazer, e, consequentemente, do desprazer, interditando, assim, a assunção de um critério que lhe permita reconhecer a irrealidade de suas percepções, de outro lado, é no interior desse funcionamento alucinatório que se realiza algo que abre o organismo a um domínio cuja marca essencial é, simultaneamente, a falta e o excesso: em uma palavra, o desejo. Falta, pois o mecanismo da regressão, na medida em que implica o investimento da percepção a partir da memória, desemboca, como vimos, na decepção e na insatisfação. Excesso, pois o surgimento dos "processos secundários" - a atividade do pensamento - descreve um movimento por meio do qual uma "parte" do complexo perceptivo é necessariamente excluída para que a imagem do objeto se constitua, de tal modo que essa "parte" excluída permanece indefinidamente à espreita do prazer, como um resto inassimilável, cuja insistência impele o aparelho a ter que produzir sempre uma imagem "a mais" no caminho da satisfação. Falta e excesso se revelam, portanto, como duas faces de um mesmo ato: aquele que consiste em representar o objeto como preexistindo à sua percepção, o que, no entanto, exige que o próprio objeto assuma inicialmente a forma de sua ausência, como vazio em torno do qual a constelação de representações orbitará, isto é, como Coisa. Nesse sentido, o caminho que leva o homem à "falsa" realidade dos fenômenos alucinatórios é o mesmo que o im-pulsiona à "verdade" de seu desejo: que a realidade não é aquilo que decreta o fim de uma batalha, mas, segundo Lacan (1954-55/1985a), o que impede que ela termine por falta de combatentes (p. 112). Da percepção ao desejo, é da mesma Coisa que se trata.

\section{REFERÊNCIAS}

Angerles, R. (1995). “Les paradoxes du 'complexe' hallucinationperception”. Revue Française de Psychanalyse, LIX, 45-472.

Associação Americana de Psiquiatria. (2014). DSM-5 - Manual diagnóstico e estatístico de transtornos mentais ( $5^{\mathrm{a}} \mathrm{ed}$. rev.). Porto Alegre: Artmed, 2014.

Assoun, P. -L. (1983). Introdução à epistemologia freudiana. Rio de Janeiro: Imago.

Baas, B. (1992). Le désir pur : À propos de "Kant avec Sade" de Lacan. In B. Baas, Le désir pur: Parcours Philosophiques dans les parages de J. Lacan. Louvain: Peeters.

Ball, B. (1890). Leçons sur les maladies mentales (2a . Ed.). Paris Asselin et Houzeau. Recuperado de http://gallica.bnf.fr/

Bercherie, P. (1989). Os fundamentos da clínica: História e estrutura do saber psiquiátrico. Rio de Janeiro: Jorge Zahar Editor.

Bercherie, P. (1983). Genèse des concepts freudiens. Paris: Navarin Éditeur.

Chatelard, D. (2005). O conceito de objeto na psicanálise: Do fenômeno à escrita. Brasília: Editora UnB.
Freud, S. (2003). Projeto de uma psicologia (O. F. Gabbi Jr., Trad.). Rio de Janeiro: Imago. (Texto original de 1895 e publicado em 1950)

Freud, S. (2015). A Interpretação dos sonhos (R. Zwick, Trad., T. Rivera, Ver.). Porto Alegre, RS: L\&PM. (Texto originalmente publicado em 1900)

Freud, S. (2004). "Formulações sobre os dois principios do acontecer psíquico”. Escritos sobre a psicologia do inconsciente, volume I: 1911-1915 (L. A. Hanns, Trad.). Rio de Janeiro: Imago. (Texto originalmente publicado em 1911)

Freud, S. (2006a). "O Inconsciente”. Escritos sobre a psicologia do inconsciente, volume II: 1915-1920(L. A. Hanns, Trad.). Rio de Janeiro: Imago Ed. (Texto originalmente publicado em 1915)

Freud, S. (2006b). "Suplemento metapsicológico à teoria dos sonhos". Escritos sobre a psicologia do inconsciente. Vol. II: 1915-1920 (L. A. Hanns, Trad.). Rio de Janeiro: Imago. (Texto original de 1915 e publicado em 1917)

Freud, S. (2006c). Além do princípio do prazer. Escritos sobre a psicologia do inconsciente. Vol. II: 1915-1920 (L. A. Hanns, 
Trad.). Rio de Janeiro: Imago. (Texto originalmente publicado em 1920)

Gabbi Jr., O. F. (2003). Notas a Projeto de uma psicologia: As origens utilitaristas da psicanálise. Rio de Janeiro: Imago Ed.

Julien, P. (1996). O Estranho gozo do próximo: Ética e psicanálise. Rio de Janeiro: Jorge Zahar Ed.

Hyppolite, Jean. (1998). "Comentário de Jean Hyppolite sobre a Verneinung de Freud”. In J. Lacan, Escritos. Rio de Janeiro: Jorge Zahar Editor. (Texto original de 1954).

Iannini, G. (2009) Estilo e verdade na perspectiva da crítica lacaniana à metalinguagem (Tese de doutorado). Universidade de São Paulo, São Paulo, SP, Brasil.

Iannini, G. (2000). "Caro Fliess, Há algo”. In Revista Curinga. Belo Horizonte, n. 14, p 59-67.

Lacan, J. (1986). Seminário Livro 1: Os escritos técnicos de Freud. Rio de Janeiro: Jorge Zahar Editor. (Texto original de 1953-54)

Lacan, J. (1985a). Seminário Livro 2: O eu na teoria de Freud e na técnica da psicanálise. Rio de Janeiro: Jorge Zahar Editor. (Texto original de 1954-55)

Lacan, J. (1985b). Seminário Livro 3: As psicoses. Rio de Janeiro: Jorge Zahar Editor. (Texto original de 1955-56)

Lacan, J. (2016). Seminário Livro 6: O desejo e sua interpretação. Rio de Janeiro: Jorge Zahar Editor. (Texto original de 1958-59)

Lacan, J. (2008). Seminário Livro 7: A ética da psicanálise. Rio de Janeiro: Jorge Zahar Editor. (Texto original de 1959-60).

Lacan, J. (1998a). Seminário Livro 11: Os quatro conceitos fundamentais da psicanálise. Rio de Janeiro: Jorge Zahar Editor. Texto original de 1964.

Lacan, J. (1966-67). Seminário Livro 14: A lógica do fantasma. Recife: Centro de Estudos Freudianos do Recife. (Texto original de 1966-67)

Lacan, J. (1998b). "De uma questão preliminar a todo tratamento possível da psicose". In Escritos. Rio de Janeiro: Jorge Zahar Editor. (Texto original de 1958)
Lacan, J. (1998c). “Observação sobre o relatório de Daniel Lagache: Psicanálise e estrutura da personalidade". In Escritos. Rio de Janeiro, Jorge Zahar Editor. (Texto original de 1960)

Lacan, J. (2003). "Da psicanálise em suas relações com a realidade". In Outros escritos. Rio de Janeiro: Jorge Zahar Editor. (Texto original de 1967)

Lacan, J. (1978). "La psychanalyse dans sa référence au rapport sexuel". In Pas tout Lacan-1926-1981. École Lacanienne de Psychanalyse. (Texto original de 1973). Recuperado de http:// ecole-lacanienne.net/wp-content/uploads/2016/04/1926-1981Pas-tout-Lacan.pdf. pp. 1503-1514.

Lanteri-Laura, G. (2000). "Signification Clinique et Psychopathologique des Hallucinations". Évolution Psychiatrique: Clinique Phénomenologique, 65, 245-254.

Lavaleé, G. (1995). "Des 'lanternes magiques' à 'l'enveloppe visuelle' du moi”. Revue Française de Psychanalyse, LIX, 427-437.

Massara, G. (2010). O estético e o ético na psicanálise: Freud, o sublime e a sublimação (Tese de doutorado). Universidade de São Paulo, São Paulo, SP, Brasil.

Masson, J. M. (1986). A correspondência completa de Sigmund Freud para Wilhem Fliess - 1887-1904. Rio de Janeiro, Imago.

Merleau-Ponty, M. (1999). Fenomenologia da percepção. São Paulo: Martins Fontes. (Texto original de 1945)

Perron, R. (1995). "Prendre pour vrai". Revue Française de Psychanalyse, LIX, 499-512.

Quercy, P. (1925). " La sensation, l'image et l'hallucination chez Taine”. L'Année Psychologique, 26, 117-150.

Soler, C. (2007). O inconsciente a céu aberto na psicose. Rio de Janeiro: Jorge Zahar Editor.

Taine, H. (1892a). De l'intelligence (T. 1). Paris : Librarie Hachette. (Texto original de 1870) Recuperado de www.gallica.bnf.fr.

Taine, H. (1892b). De l'intelligence (T. 2). Paris, Librarie Hachette. (Texto original de 1870) Recuperado de www.gallica.bnf.fr. 